\title{
Clinico-radiological Outcome after Ponseti Technique for Bilateral Idiopathic Congenital Talipes Equinovarus
}

\author{
Ujjwal K Debnath ${ }^{1}$, Gourab Chatterjee ${ }^{2}$
}

\begin{abstract}
Aim and objective: Ponseti method is a well-established treatment method for clubfeet. It has been suggested that pooling of data for unilateral and bilateral idiopathic congenital talipes equinovarus (ICTEV) is not appropriate. Therefore, this study aimed to evaluate the clinical and radiological outcome and their correlation in bilateral clubfeet.

Materials and methods: Thirty infants (19M:11F) with bilateral ICTEV underwent the Ponseti method of treatment. Pirani scores and X-rays were recorded at the first visit (pre-treatment) and at the end of 12 months (post-treatment). Radiological angles were measured on anteroposterior (AP) and lateral (Lat) views of the foot and ankle.

Results: The mean age was $6.7 \pm 3.4$ weeks (range $1-11$ weeks). The mean initial Pirani score was $4.28 \pm 1.1$ (left) and $4.23 \pm 1.09$ (right). Successful outcomes were observed in $27 / 30(90 \%)$ and $28 / 30(93 \%)$ of the left and right foot, respectively. The mean number of casts required for left and right were $(5.3 \pm 1.1)$ and $(4.9 \pm 1.0)$, respectively. Achilles tendon (TA) tenotomy was performed in $76 \%$ (left) and $73 \%$ (right) feet. The postprocedure Pirani scores significantly correlated with talocalcaneal angle on AP (TCAP) and lateral views $(T C L)$ on left $\left(r_{\text {AP }}=0.63, r_{\text {Lat }}\right.$ $=0.76)$ and right feet $\left(r_{\mathrm{AP}}=0.65, r_{\text {Lat }}=0.73\right)(p<0.01)$. Talocalcaneal index (TCI) has been significantly correlated with postprocedure Pirani score in left $(r=0.77)$ and right $(r=0.64)$ feet $(p<0.01)$. Tibiocalcaneal lateral angle (TiCL) has been significantly correlated with postprocedure Pirani score in the left feet $(p<0.01)$.

Conclusion: Bilateral ICTEV can be treated successfully by the Ponseti method in infants. There was a good correlation between clinical scores and radiological parameters.

Keywords: Bilateral, Clubfeet, Congenital talipes equinovarus, Ponseti technique.

Journal of Foot and Ankle Surgery (Asia Pacific) (2021): 10.5005/jp-journals-10040-1171
\end{abstract}

\section{INTRODUCTION}

It is almost universally accepted that the initial treatment of the idiopathic congenital talipes equinovarus (ICTEV) should be non-operative irrespective of the deformity severity. ${ }^{1}$ Ponseti method includes serial corrective manipulation, a specific cast application technique, and may be followed by a percutaneous Achilles tenotomy under local anesthesia. ${ }^{2-5}$ Ponseti himself has excellent outcome avoiding the need for surgery in $89 \%$ of his series of patients. ${ }^{2}$

A large number of clinical and radiological parameters have been described to assess the anatomical deviations. Dimeglio et al., ${ }^{6}$ Pirani et al., ${ }^{7}$ and Laaveg and Ponseti ${ }^{2}$ described some of the very commonly used clinical scores to assess clubfoot. However, the utility of radiographic parameters and clinical assessment parameters is still debated. ${ }^{8,9}$ Some authors have reported statistically significant correlations between clinical outcome and radiographic results, ${ }^{2,10}$ whereas others have found no relationship between the two. ${ }^{11}$

The purpose of this study was to evaluate the outcome of treatment of bilateral ICTEV with the Ponseti technique with reference to clinical and radiological parameters and assessing the correlation between clinical and radiological outcomes.

\section{Materials and Methods}

Thirty-one consecutive patients with bilateral club feet (ICTEV) underwent treatment with the Ponseti method. All but one patient was assessed clinically and radiologically before the treatment, assessed each time of casting and after the follow-up period of

\footnotetext{
${ }^{1}$ Jagannath Gupta Institute of Medical Sciences and Hospital, Kolkata, West Bengal, India

${ }^{2}$ Department of Orthopaedics, Ramakrishna Mission Seva Pratishthan, Kolkata, West Bengal, India

Corresponding Author: Ujjwal K Debnath, Jagannath Gupta Institute of Medical Sciences and Hospital, Kolkata, West Bengal, India, Phone: +919051588823, e-mail: debs10uk@gmail.com

How to cite this article: Debnath UK, Chatterjee G. Clinico-radiological Outcome after Ponseti Technique for Bilateral Idiopathic Congenital Talipes Equinovarus. J Foot Ankle Surg (Asia Pacific) 2021;8(3):145-151. Source of support: Nil

Conflict of interest: None
}

12 months. The parents of one patient who presented at an age of 10 weeks did not want this treatment and therefore was excluded. An approval from the Institutional Ethics Committee for research on human subjects was granted by the institution board. The data were recorded and analyzed prospectively. We excluded infants with unilateral clubfeet, above the age of 3 months, with other etiologies, e.g., neuromuscular disease or as part of a syndrome and any previous treatment.

The treatment phase starts with the first cast aiming to align the forefoot with the midfoot and hindfoot (Fig. 1). The cavus deformity was usually corrected after the first cast. Weekly plasters were applied till $70^{\circ}$ of abduction with feet in supination was achieved.

Four to six long leg casts changed weekly after manipulation of the foot (Ponseti technique) were carried out. On average, five casts were required to correct the deformity (Fig. 2A). At 

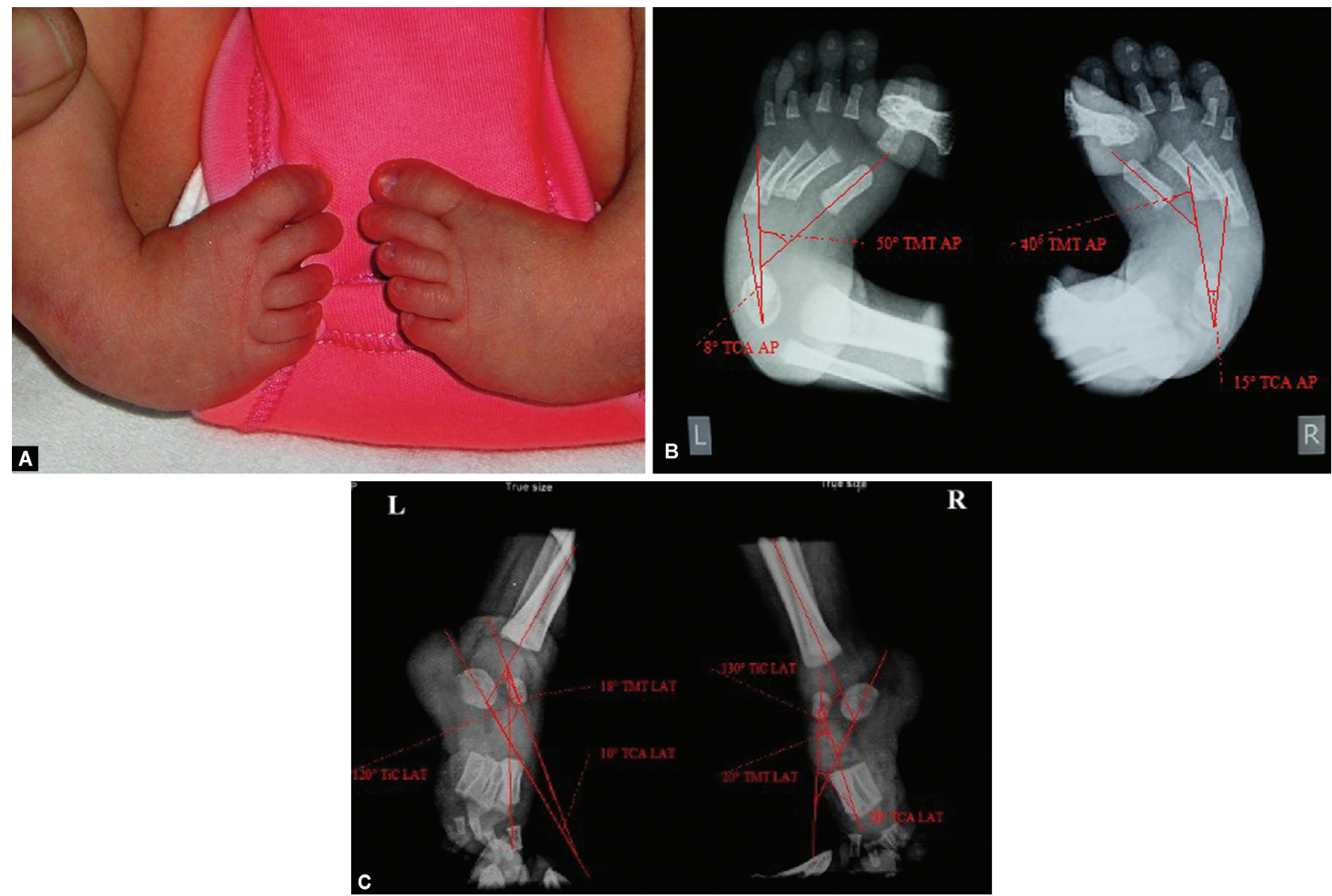

Figs 1 A to C: (A) A 4-week-old female child with bilateral severe clubfeet at initial presentation; (B) Initial X-rays (anteroposterior views) of both feet; (C) Initial X-rays (lateral views) of both feet
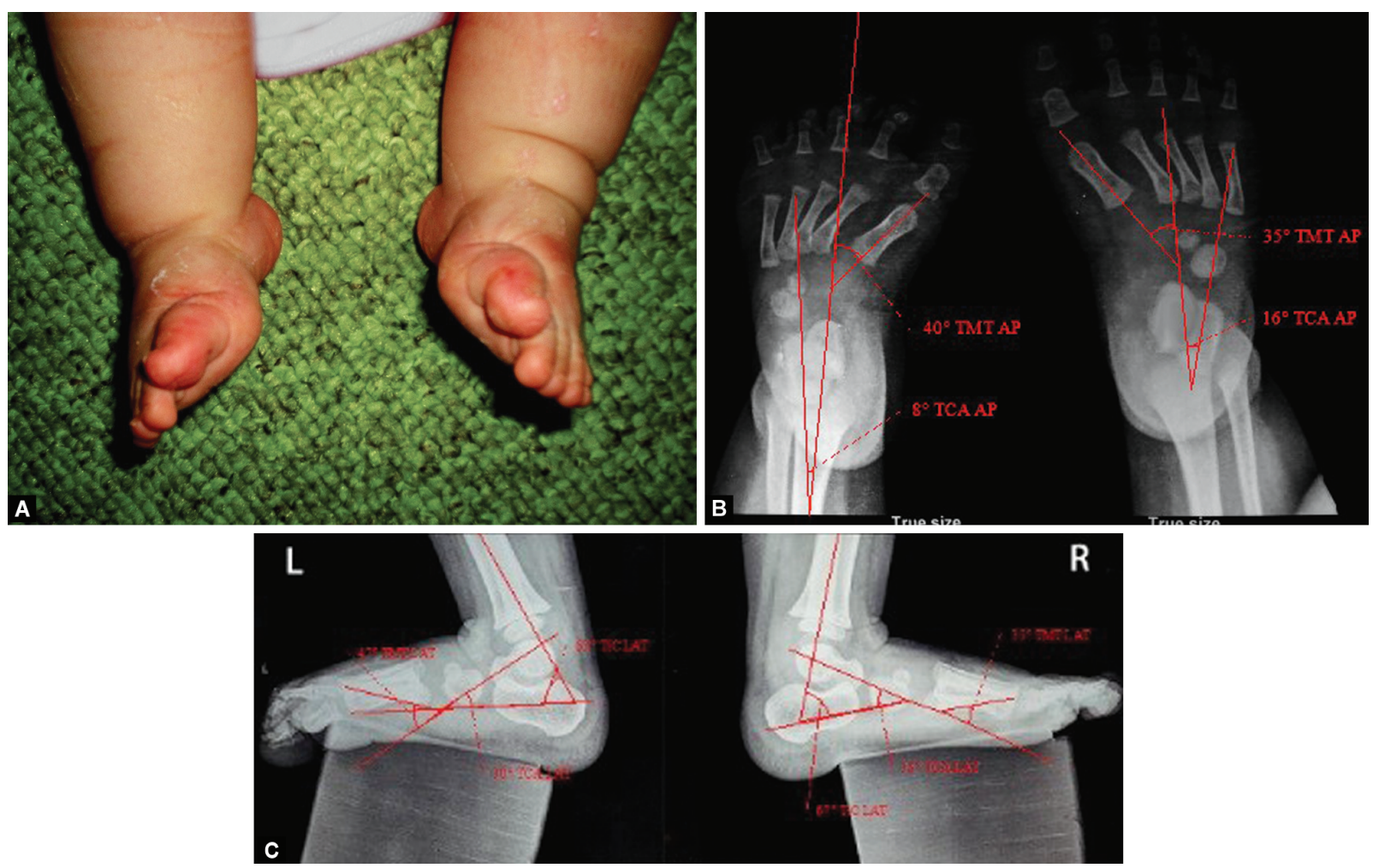

Figs 2A to C: (A) Clinical photo of the same girl after 6 casts at 6 weeks of treatment; (B) X-rays (anteroposterior views) of both feet at 6 weeks; (C) $X$-rays (lateral views) of both feet at 6 weeks 
each follow-up, the foot was evaluated for deformity correction using the Pirani score. If there was residual equinus observed with a Pirani heel score of $>1$, after sufficient manipulation a simple percutaneous tenotomy of the Achilles tendon (TA) was performed. The final cast was applied with the foot in $70^{\circ}$ of abduction and $10-15^{\circ}$ of dorsiflexion (Fig. 3). A brace was applied after 3 weeks of tenotomy. The brace was applied for 23 hours a day for the first 3 months. This was followed up with a nighttime brace only for 2-4 years. Custom-made shoes were used once the child started walking. All children were seen every three months till the patient was 3 years of age.

\section{Clinical Scores}

Clinical scores (Pirani scores) were recorded at the first visit (pretreatment) (Fig. 1A) and at the end of 12 months (post-treatment)

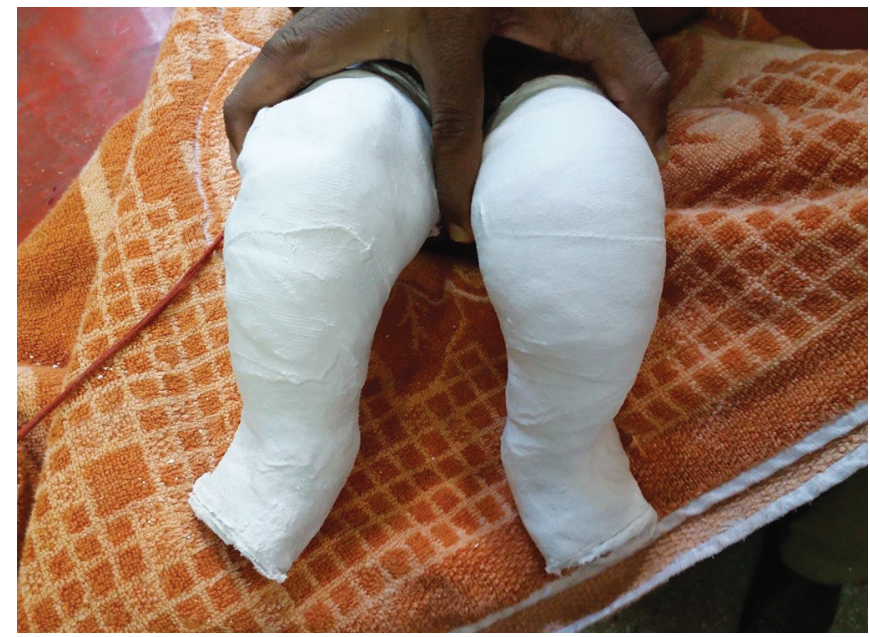

Fig. 3: Both feet after TA tenotomy in the cast at $70^{\circ}$ abduction of the same child
(Fig. 4A). The final outcome was categorized as excellent, good, and poor. When Pirani score was $<0.5$, it was graded as excellent, when it became $0.5-1.0$, it was graded as good and poor outcome occurs when the score became $>1.0$.

\section{Radiographic Measurements}

Radiographs were taken at the first visit before treatment and were repeated at the end of treatment when the foot was deemed to be normal as per the Pirani score. Radiological parameters were measured on anteroposterior (AP) and lateral (Lat) views of the foot and ankle (Figs 1B, 1C, 2B, 2C, 4B and 4C).

Anteroposterior projection: the hip and knee flexed were to $90^{\circ}$ and the foot was placed plantigrade onto an X-ray cassette with maximal ankle dorsiflexion. The $\mathrm{X}$-ray beam was directed toward the cassette tilted $30^{\circ}$ from the perpendicular toward the talar head. Lines were drawn on the AP view longitudinally through the osseous nucleus of the talus parallel to its medial border and through the calcaneus parallel to its lateral border. An additional line was drawn through the longitudinal axis of the first metatarsal. In the AP view, two angles were evaluated; the talocalcaneal angle (TCAP) and the talo-first metatarsal (T1MTAP) angle.

Lateral projection: the medial aspect of the foot, ankle, and knee were placed against an X-ray cassette with maximal ankle dorsiflexion. The X-ray beam was directed perpendicular to the cassette. Lines were drawn on the lateral view longitudinally through the central axis of the talus and parallel to the lower border of the calcaneus. Another line was drawn through the axis of the first metatarsal. In this projection, the talocalcaneal angle (TCL), tibiocalcaneal (TiCL), and talo-first metatarsal angles (T1MTL) were measured. The talocalcaneal index $(\mathrm{TCl})$, which is the sum of the talocalcaneal angles in the AP and lateral projections, was also calculated.

Statistical analysis was carried out using SPSS software v. 22 with appropriate statistical tests (Chi-square test, paired T-test, Wilcoxon
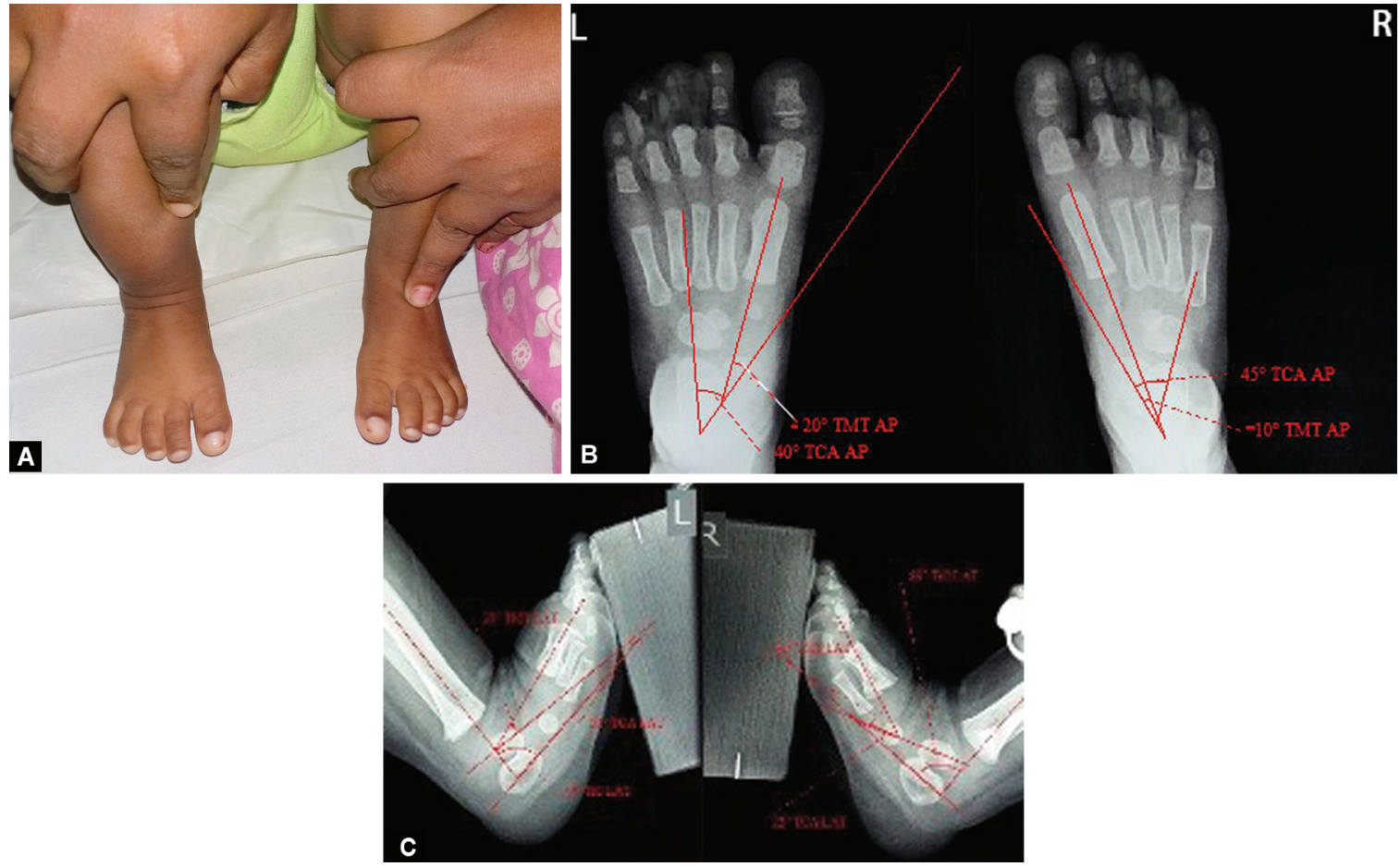

Figs 4A to C: (A) Final plantigrade feet at final follow-up; (B) X-rays (anteroposterior views) of both feet; (C) X-rays (lateral views) of both feet 
Signed-Rank test, Pearson correlation coefficient) to determine significance level. All the results were considered statistically significant at $p<0.05$.

\section{Results}

Thirty patients (19M:11F) in this series with bilateral ICTEV underwent cast treatment (Table 1). The mean age of presentation of the patients was $6.73 \pm 3.42$ weeks (range 1-11 weeks). 9/30 (30\%) infants were between 1 week and 4 weeks. The mean age (mean \pm SD) of males was $5.68 \pm 3.28$ weeks (range 1-11 weeks). The mean age (mean $\pm \mathrm{SD}$ ) of females was $8.54 \pm 2.97$ weeks (range 1-11 weeks). The mean age of presentation of females was significantly higher than that of males $\left(t_{28}=2.37 ; p=0.025\right)$.

The total mean Pirani score at presentation was $4.45 \pm 1.19$ (left) and $4.39 \pm 1.15$ (right). The post-treatment mean Pirani scores were lower in both feet as compared to pre-treatment Pirani scores (Table 2A). Good to excellent outcomes were observed in $27 / 30(90 \%)$ and $28 / 30$ (93\%), respectively, in the left and right foot (Table 2A). A significant difference between the mean initial scores for tenotomy and non-tenotomy groups was noted. There were significant differences in the mean hindfoot scores for both groups. There was no significant difference between the midfoot scores for both groups (Table 2B).

The mean number of casts required for the left side was $5.3 \pm$ 1.1 (mean \pm SD) with a range of $4-8$ casts. The mean number of casts required for the right side was $4.9 \pm 1.0$ (mean \pm SD) with a range of $4-8$ casts (Table $2 \mathrm{C}$ ). Though the number of casts required in right was less than the left, there was no significant difference in the mean number of casts required between the two sides $\left(t_{58}=1.34\right.$; $p=0.18)$. The majority of clubfoot (80\%) were treated for 5 weeks.

Table 1: Age and gender at presentation

\begin{tabular}{lll}
\hline Age of presentation (weeks) & Numbers & Percentage \\
\hline $1-4$ & $9(8 \mathrm{M}: 1 \mathrm{~F})$ & 30 \\
$5-9$ & $14(9 \mathrm{M}: 5 \mathrm{~F})$ & 46.7 \\
$10-11$ & $7(2 \mathrm{M}: 5 \mathrm{~F})$ & 23.3 \\
Total & $30(19 \mathrm{M}: 11 \mathrm{~F})$ & 100 \\
\hline
\end{tabular}

Table 2A: Clinical results (Pirani score)

\begin{tabular}{|c|c|c|c|}
\hline Clinical scores & Left $(n=30)$ & Right $(n=30)$ & $p$ value \\
\hline Pre-treatment Pirani & $4.28 \pm 1.1^{a}$ & $4.23 \pm 1.09^{b}$ & $\begin{array}{l}0.84^{\mathrm{a}-\mathrm{b}} \\
<0.0001^{\mathrm{a}, \mathrm{c}}\end{array}$ \\
\hline Post-treatment Pirani & $0.85 \pm 0.74^{c}$ & $0.71 \pm 0.60^{d}$ & $\begin{array}{l}0.64^{c-d}, \\
<0.0001^{b-d}\end{array}$ \\
\hline Excellent $(<0.5)$ & (6) $20 \%$ & (9) $30 \%$ & $<0.05$ \\
\hline Good (0.5-1.0) & (21) $70 \%$ & (19) $63.3 \%$ & 0.64 \\
\hline Poor $(>1.0)$ & (3) $10 \%$ & (2) $6.7 \%$ & 0.47 \\
\hline
\end{tabular}

${ }^{a-c, b-d}$ Wilcoxon Signed rank test, ${ }^{a-b, c-d} t$-test
Achilles tendon tenotomy was performed in $76 \%$ and $70 \%$ for the left and right feet, respectively. Achilles tendon tenotomy required was higher for the left side than that of the right side but it was not significant $(Z=0.95 ; p=0.34$ ) (Table $2 C$ ). Adequate forefoot abduction was achieved before doing tenotomy for the 21 patients with bilateral deformity.

We were able to achieve good results in 55 clubfeet (91\%). Only two children (both feet) and one child with a left foot had poor results. Three (3/7) children who had presented late beyond 10 weeks of age with more rigid club foot than others (Pirani scores $>$ 5) underwent serial casting for another 5 weeks. All three patients were corrected after extra 5 weeks of casting.

At the latest follow-up of 1 year, there was no limitation of activities whatsoever in $90 \%$ of the children, and none had limitations during normal activities. Two children were not able to heel-strike properly at the beginning of the stance phase. These two children with poor outcomes had to have a second TA tenotomy at 12 months with corrected casting for further 5 weeks.

The radiological indices for post-treatment mean scores showed significant improvement for both feet as compared to pretreatment scores. The postprocedure mean talocalcaneal angle on AP (TCAP) and lateral views (TCL) was significantly higher than that of the preprocedure mean for left and right $(p<0.0001)$ (Table $3 A)$. The postprocedure mean $\mathrm{TCl}$ was significantly higher than that of preprocedure mean scores for left and right $(p<0.0001)$ (Table 3A).

The postprocedure mean talo-first TMT angle on AP view (T1MTAP) was significantly lower than that of the preprocedure mean score for left $(p<0.05)$ and mean score for right $(p<0.0001)$ (Table 3B). The postprocedure mean talo-first TMT angle on lateral view (T1MTL) was significantly higher than that of the preprocedure mean score for left $(p<0.05)$ and mean score for right $(p<0.0001)$ (Table 3B). The postprocedure mean TiCL was significantly lower than that of preprocedure for left and right foot $(p<0.0001)$ (Table 3C).

\section{Clinico-radiological Correlation}

The preprocedure Pirani score significantly correlated with radiological parameters, i.e., TCAP and TCL in the left $\left(r_{\mathrm{AP}}=0.46, r_{\text {Lat }}\right.$ $=0.64)$ and right feet $\left(r_{\mathrm{AP}}=0.67, r_{\text {Lat }}=0.62\right)(p=0.01)$. Talocalcaneal index has been significantly correlated with preprocedure Pirani score in the left $(r=0.58)$ and right $(r=0.82)$ feet $(p<0.05)$ (Tables 4A and $B)$.

The postprocedure Pirani scores significantly correlated with TCAP and TCL $\left(r_{\mathrm{AP}}=0.63, r_{\text {Lat }}=0.76\right)$ and right feet $\left(r_{\mathrm{AP}}=0.65, r_{\text {Lat }}=\right.$ $0.73)(p<0.01)$. Talocalcaneal index has been significantly correlated with postprocedure Pirani score in the left $(r=0.77)$ and right $(r=$ $0.64)$ feet $(p<0.01)$ (Tables 4 A and B). Tibiocalcaneal lateral angle has been significantly correlated with postprocedure Pirani score in left sided feet $(p<0.01)$.

There was no significant clinical correlation with either pre- or post-treatment Pirani scores of talo-first MT angle AP or lateral view angles (Tables $4 \mathrm{~A}$ and $\mathrm{B}$ ).

Table 2B: Association of pre-treatment Pirani scores with tenotomy vs non-tenotomy group

\begin{tabular}{|c|c|c|c|c|c|}
\hline \multirow[b]{2}{*}{ Component } & \multicolumn{2}{|c|}{ Tenotomy (45) } & \multicolumn{2}{|c|}{ Non-tenotomy (15) } & \multirow[b]{2}{*}{$p$ value* } \\
\hline & Left (23) & Right (22) & Left (7) & Right (8) & \\
\hline Initial Pirani Score & $4.45 \pm 1.19^{a}$ & $4.39 \pm 1.15^{c}$ & $4.11 \pm 1.01^{b}$ & $4.07 \pm 1.02^{d}$ & $0.012^{\mathrm{a}-\mathrm{b}}, 0.011^{\mathrm{c}-\mathrm{d}}$ \\
\hline Hindfoot score & $2.41 \pm 0.42^{\mathrm{a}}$ & $2.37 \pm 0.45^{c}$ & $2.24 \pm 0.56^{b}$ & $2.22 \pm 0.54^{d}$ & $0.015^{a-b}, 0.014^{c-d}$ \\
\hline Midfoot score & $2.04 \pm 0.56^{\mathrm{a}}$ & $2.02 \pm 0.54^{c}$ & $1.86 \pm 0.45^{b}$ & $1.85 \pm 0.46^{d}$ & $0.14^{a-b}, 0.15^{c-d}$ \\
\hline
\end{tabular}

Left side $a-b(*)$ Chi-square test

Right side c-d $(*)$ Chi-square test 
The complications during treatment were pressure sores (8), skin abrasion (1), and cast slippage (1) which were managed with observation. There was no significant difference in the proportions of complications between the two sides $(Z=1.38 ; p=0.16)$ (Table 5 ).

\section{Discussion}

Birth prevalence of clubfoot varies between 0.51 and 2.03/1,000 live births in low- or middle-income countries. ${ }^{12}$ Clubfoot is a deformity that is quite prevalent in India with an incidence of about 1.19 per 1,000 live birth. ${ }^{11,13}$ About $50 \%$ of the infants born with clubfoot have a bilateral deformity. ${ }^{14,15}$ This complex deformity of both feet in an infant requires early detection and meticulous treatment by the treating physician. The whole process of treatment also

Table 2C: Number of casting and tendoachilles tenotomy required for all patients

\begin{tabular}{llll}
\hline Procedures & Left & Right & p value \\
\hline No. of cast & $5.3 \pm 1.1(4-8)$ & $4.9 \pm 1(4-8)$ & $0.18^{*}$ \\
TA tenotomy & $23 / 30(76 \%)$ & $21 / 30(70 \%)$ & $0.34^{*}$ \\
\hline
\end{tabular}

$(*)$-test requires education of parents and their active participation in the treatment process. ${ }^{15}$

In this series, $76.7 \%$ were below the age of 2 months of which infants were $30 \%$. This is similar to the previous studies published in India and Bangladesh. ${ }^{16,17}$ Growing awareness and education of parents relates to the early presentation in these countries. In the present study, the mean age at initial presentation was 6.7 weeks comparable with Laaveg and Ponseti's study. ${ }^{2}$ The female children had a late presentation. Social bias and less attention toward female infants in this region may account for the lower incidence in females.

The most popular scoring system is Pirani scoring for clubfeet. ${ }^{18}$ Pirani's scoring is widely accepted because it is simple, reliable, quick, cost-effective, easy to learn, use, and apply. ${ }^{19}$ The number of casts required and the probability of TA tenotomy can be predicted by Pirani scoring system. ${ }^{20}$

Gray et al. observed that bilateral clubfeet were highly correlated in initial severity, the number of Ponseti casts required to correct initial deformity, the need for Achilles tenotomy, and the rate of relapse. ${ }^{21}$ The outcome in bilateral ICTEV has only been provided as a part of the combined unilateral and bilateral cases in few published articles.

Table 3A: Pre- and post-treatment radiological indices (talocalcaneal angle and index)

\begin{tabular}{|c|c|c|c|c|c|c|}
\hline & \multicolumn{3}{|c|}{ Pre Rx } & \multicolumn{3}{|c|}{ Post Rx } \\
\hline & \multicolumn{2}{|c|}{ Talocalcaneal angle $\left({ }^{\circ}\right)$} & \multirow[t]{2}{*}{ Talocalcaneal index $\left({ }^{\circ}\right)$} & \multicolumn{2}{|c|}{ Talocalcaneal angle $\left({ }^{\circ}\right)$} & \multirow[t]{2}{*}{ Talocalcaneal index $\left({ }^{\circ}\right)$} \\
\hline & $A P$ & Lat & & $A P$ & Lat & \\
\hline Left & $10.2 \pm 3.7^{\mathrm{a}}$ & $20.0 \pm 8.3^{c}$ & $30.2 \pm 10.1^{i}$ & $20.7 \pm 9.0^{b}$ & $28.0 \pm 11.2^{d}$ & $48.8 \pm 18.5^{j}$ \\
\hline Right & $11.4 \pm 4.3^{\mathrm{e}}$ & $18.2 \pm 8.7^{9}$ & $29.6 \pm 11.4^{k}$ & $28.1 \pm 7.7^{f}$ & $32.7 \pm 9.5^{\mathrm{h}}$ & $60.5 \pm 15.1^{1}$ \\
\hline
\end{tabular}

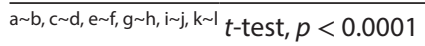

Table 3B: Pre- and post-treatment radiological indices (Talo-first MT angle-AP and Lat)

\begin{tabular}{|c|c|c|c|c|}
\hline \multirow[b]{3}{*}{ Side } & \multicolumn{2}{|c|}{ Pre $R x$} & \multicolumn{2}{|c|}{ Post Rx } \\
\hline & \multicolumn{2}{|c|}{ Talo-first MT angle $\left({ }^{\circ}\right)$} & \multicolumn{2}{|c|}{ Talo-first MT angle $\left({ }^{\circ}\right)$} \\
\hline & $A P$ & Lat & $A P$ & Lat \\
\hline Left & $8.5 \pm 14.6^{a}$ & $19.6 \pm 14.0^{c}$ & $0.5 \pm 20.2^{b}$ & $25.9 \pm 17.4^{\mathrm{d}}$ \\
\hline Right & $6.4 \pm 12.5^{\mathrm{e}}$ & $20.2 \pm 12.5^{\mathrm{g}}$ & $-9.4 \pm 18.6^{f}$ & $28.5 \pm 14.9^{h}$ \\
\hline
\end{tabular}

Table 3C: Pre- and post-treatment radiological indices (tibiocalcaneal angle Lat)

\begin{tabular}{lll}
\hline Side & $\begin{array}{l}\text { Pre Rx (tibiocalcaneal } \\
\text { angle-Lat) }\end{array}$ & $\begin{array}{l}\text { Post } R x \text { (tibiocalcaneal } \\
\text { angle-Lat) }\end{array}$ \\
\hline Left & $94.1 \pm 11.3^{\mathrm{a}}$ & $67.5 \pm 14.4^{\mathrm{b}}$ \\
Right & $87.6 \pm 17.7^{\mathrm{c}}$ & $63.9 \pm 10.6^{\mathrm{d}}$ \\
\hline $\mathrm{a} \sim \mathrm{b}$-test, $p<0.0001,{ }^{c \sim \mathrm{d}} t$-test $p<0.0001$ &
\end{tabular}

Table 4A: Correlation between Pirani scores and radiological parameters

\begin{tabular}{lllllll}
\hline & \multicolumn{9}{c}{ Left } \\
\cline { 2 - 7 } & TCAP & TCL & TCI & T1MTAP & T1MTL & Ti-CL \\
\hline Pre-Rx Pirani & $-0.46\left(^{*}\right)$ & $-0.64\left(^{*}\right)$ & $-0.58\left(^{*}\right)$ & $0.33(0.08)$ & $-0.17(0.67)$ & $0.08(0.67)$ \\
Post-Rx Pirani & $-0.63\left(^{*}\right)$ & $-0.76\left(^{*}\right)$ & $-0.77\left(^{*}\right)$ & $0.34(0.11)$ & $-0.29(0.34)$ & $0.52(*)$ \\
\hline
\end{tabular}

$(*)=p<0.05$

Table 4B: Correlation between Pirani scores and radiological parameters

\begin{tabular}{lllllll}
\hline & \multicolumn{9}{c}{ Right } \\
\cline { 2 - 7 } & TCAP & TC Lat & TC Index & TMT AP & TMT Lat & Ti-C Lat \\
\hline Pre-Rx Pirani & $-0.67\left(^{*}\right)$ & $-0.74\left(^{*}\right)$ & $-0.82\left(^{*}\right)$ & $0.31(0.09)$ & $-0.29(0.12)$ & $0.38\left(^{*}\right)$ \\
Post-Rx Pirani & $-0.65\left(^{*}\right)$ & $-0.73\left(^{*}\right)$ & $-0.64\left(^{*}\right)$ & $0.42(0.02)$ & $-0.29(0.12)$ & $0.49\left(^{*}\right)$ \\
\hline
\end{tabular}

$(*)=p<0.05$ 
Table 5: Complications after treatment

\begin{tabular}{lllll}
\hline & \multicolumn{2}{c}{ Left side $(n=30)$} & \multicolumn{2}{c}{ Right side $(n=30)$} \\
\cline { 2 - 5 } Complications & Number & $\%$ & Number & $\%$ \\
\hline Skin abrasion & 1 & 3.3 & 0 & 0.0 \\
Pressure sores & 5 & 16.7 & 3 & 10.0 \\
Cast slippage & 1 & 3.3 & 0 & 0.0 \\
\hline
\end{tabular}

Bor et al. treated $43 / 74$ children with bilateral ICTEV with a long 5-year follow-up. The mean pre-treatment Pirani scores were 5.08 \pm 1.29 . The successful outcome was achieved in $89 \%$ of children. ${ }^{22}$ Bhatiwal et al. had treated $156 / 300$ children with bilateral clubfeet (mean pre-treatment Pirani scores was 5.5) were treated with the Ponseti technique with a successful outcome in $92 \%$ of patients. Percutaneous tendoachilles tenotomy was done in $78 \%$ of cases. ${ }^{23}$ The mean pre-treatment Pirani scores in our series were lower than the previously reported series. ${ }^{17,22,24}$

Saini et al. presented a series of 50 cases (76 feet) where most of the children were below 6 weeks of age. ${ }^{25}$ They classified the Pirani scores into three groups, i.e., group I $(<2.5)$, group II (3-4.5), and group III (>5). Their series had 26 (52\%) bilateral foot involvement with $79 \%$ successful outcomes. Feet classified into group II and III had mean Pirani scores of 4.13 and 5.42, respectively. Considering this severity classification, most of our patients fell in group II. The incidence of tenotomy was less in patients presenting at an early age as compared to patients with the late initial presentation.

Lehman et al. found the Pirani score changed from 4.6 to 0.6 with a mean of 5.3 casts in children below the age of 1 year at presentation. ${ }^{26}$ The number of casts per foot in our study was a mean 5.3 for left and 4.9 for right. The number of casts per foot was 5 to 10 (average 7.6) in a series by Ponseti et al. ${ }^{27}$ The mean number of casts during their treatment was seven in a series by Laaveg et al. ${ }^{2}$ Morcuende et al. reported that $90.0 \%$ had five or fewer casts. ${ }^{28}$ Our study had a similar outcome for patients presenting early after birth who required a fewer number of casts compared to those who presented late. The change in Pirani score between pre- and posttreatment values was found to be statistically significant.

Both tenotomy and non-tenotomy groups showed a strong positive correlation between the initial Pirani score and the number of casts required to correct the deformity. But the study did not mention several bilateral feet requiring tenotomy. ${ }^{29}$ The worldwide literature suggested $78-97 \%$ of children required TA tenotomy. $2,5,7,15,17,18,22,24-30$ Only Scher et al. and Kulambi et al. reported 72 and $67 \%$ TA tenotomy in their reported case series. ${ }^{31,32}$ The number of patients requiring tenotomy in our series was less (76\% for left and $73 \%$ for right). This may be because the majority of the patients presenting at an early age had less rigid foot with moderate deformity and low Pirani scores.

There is no consensus on the reliability and reproducibility of correlation between clinical and radiological parameters. ${ }^{23}$ Since there was no agreement between clinical and radiological evaluation due to significant deviation in the range of angle values in the individual groups, the radiological angle measurements are to be viewed critically. ${ }^{10,11}$ The variation in findings may be attributed to the difficulty in obtaining radiographs in children, inaccuracies in measurement, use of different functional rating systems, or different patient inclusion criteria. ${ }^{33}$ In a recent study, the lateral view with the foot in maximal dorsiflexion was found to be the most significant and useful view to detect abnormality in Ponseti-treated clubfeet. ${ }^{34}$
A study by Zimmerman et al. suggested that reproducible radiographic measurements can be made using forced lateral radiographs in infants with clubfeet and correlate these measurements with clinical outcomes which can indicate future recurrence..$^{35,36}$ In our study, the TCAP and TCL have a significant correlation independently in either foot. In a meta-analysis, it was found that a higher TCAP angle was associated with a better functional outcome. ${ }^{37}$ The $\mathrm{TCl}$ has been recognized as one of the very good indicators of hind-foot varus deformity. ${ }^{38}$ In our series, $\mathrm{TCl}$ of both feet were positively correlated $(p<0.0001)$ with Pirani scores. Talocalcaneal index was found to have a strong association with clinical results in one previous study. ${ }^{39}$ No statistically significant correlation was found between Talofirst MT AP and lateral angles with Pirani scores, i.e., $p=0.09$ and $p=0.12$, respectively. This has been previously suggested by many authors and therefore this was no surprise. ${ }^{14}$ The tibiocalcaneal and tibiotalar angles in the lateral view showed a statistically significant correlation similar to our study. ${ }^{33}$ The $\mathrm{TiC}$ lateral angles were significantly correlated with the Pirani scores in the post-treatment stage. The TiC-lateral angle after treatment had a mean value of $64.32^{\circ}$ with a range of $46-87^{\circ} .40$ In a study by Radler et al., the mean TiC-lateral after treatment was $68.72{ }^{\circ}{ }^{41}$ Although the TiC-lateral is a good parameter to study the correction of equinus after treatment, they did not correlate equally in both feet in the present series. This is possibly due to the right-handedness of the surgeon or incomplete tenotomy. We emphasize that the $\mathrm{TiC}$ lateral and $\mathrm{TCl}$ are the most important radiological parameters to measure the hindfoot equinus and these measurements can assess the correction achieved. The real challenge is the borderline cases that relapse at follow-up in the first year where a radiograph may help to correlate the correction of hindfoot equinus.

The strengths of the study were: (1) A prospective case series study, (2) Completed follow-up, with no drop out of patients, (3) Independent assessment of clinical and radiological outcome. The limitations of the study include small sample size, lack of a control group, short follow-up, not a blinded study and syndromic feet are not included in the study. There was one radiological limitation that is worth mentioning. The stress lateral radiograph is perhaps the most useful one to assess the hindfoot dorsiflexion. Since the Pirani score requires appropriate stress on the foot to assess the correction it has a poor correlation to the static AP radiograph. ${ }^{40,41}$

\section{Conclusion}

The aim of obtaining straight, painless, plantigrade flexible, normallooking feet was achieved by the Ponseti method in bilateral ICTEV in infants presenting at an early age. The procedure could be correlated both clinically and radiologically. We recommend this treatment for infants in India with bilateral clubfeet which can correct and prevent future complications if treatment is started early. The successful outcome can also be attributed to the education of parents and caregivers who actively participated in the whole treatment. The radiographic examinations are not necessary for the routine treatment of congenital clubfoot, especially if treated with the Ponseti method. However, in some selected cases, the radiographic examination can be useful; e.g., in cases in which the surgeon is unsure of the need for percutaneous tenotomy because the position of the calcaneus appeared clinically high but the foot has good dorsiflexion, a radiographic examination is indicated as well as in other particular cases. 


\section{References}

1. Cummings RJ, Davidson RS, Armstrong PF, et al. Congenital clubfoot. J Bone Joint Surg Am 2002;84-A(2):290-308. DOI: 10.2106/00004623200202000-00018.

2. Laaveg SJ, Ponseti IV. Long-term results of treatment of congenital clubfoot. J Bone Joint Surg Am 1980;62(1):23-31. DOI: 10.2106/00004623-198062010-00004.

3. Ponseti IV, Campos J. Observations on pathogenesis and treatment of congenital clubfoot. Clin Orthop Relat Res 1972;84:50-60. DOI: 10.1097/00003086-197205000-00011.

4. Ponseti IV. Current concept review: treatment of congenital clubfoot. J Bone Joint Surg Am 1992;74-A(3):448-454. DOI: 10.2106/00004623199274030-00021.

5. Pavone V, Testa G, Costarella L, et al. Congenital idiopathic talipes equinovarus: an evaluation in infants treated by the Ponseti method. Eur Rev Med Pharmacol Sci 2013;17(19):2675-2679.

6. Diméglio $A$, Bensahel $H$, Souchet $P$, et al. Classification of clubfoot. J Pediatr Orthop 1995;4(2):129-136. DOI: 10.1097/01202412-19950402000002.

7. Pirani S, Outerbridge HK, Sawatzky B, et al., (1999) A reliable method of clinically evaluating a virgin clubfoot evaluation. 21st SICOT Congress.

8. Roye BD, Vitale MG, Gelijns AC, et al. Patient based outcomes after clubfoot surgery. J Pediatr Orthop 2001;21(1):42-49. DOI: 10.1097/01241398-200101000-00010.

9. Uglow MG, Clarke NMP. The functional outcome of staged surgery for the correction of talipesequinovarus. J Pediatr Orthop 2000;20(4):517-523. DOI: 10.1097/01241398-200007000-00018.

10. Yamamoto $\mathrm{H}$, Furuya $\mathrm{K}$. One stage postero medial release of congenital clubfoot. J Pediatr Orthop 1988;8(5):590-595. DOI: 10.1097/01241398-198809000-00018.

11. Herbsthofer B, Eckardt A, Rompe JB, et al. Significance of radiographic angle measurements in evaluation of congenital clubfoot. Arch Orthop Trauma Surg 1998;17(6-7):324-329. DOI: 10.1007/ s004020050259.

12. Smythe T, Kuper $H$, Macleod D, et al. Birth prevalence of congenital talipes equinovarus in low- and middle-income countries: a systematic review and meta-analysis. Trop Med Int Health 2017;22(3):269-285. DOI: 10.1111/tmi.12833.

13. Mittal R, Sekhon A, Singh G, et al. The presence of congenital orthopaedic anomalies in a rural community. Int Orthop 1993;17(1):1112. DOI: 10.1007/BF00195214.

14. Ansar A, Rahman AE, Romero L, et al. Systematic review and metaanalysis of global birth prevalence of clubfoot: a study protocol. BMJ Open 2018;8(3):e019246. DOI: 10.1136/bmjopen-2017-019246.

15. Dobbs MB, Rudzki JR, Purcell DB, et al. Factors predictive of outcome after use of Ponsenti method for treatment of idopathic clubfeet. J Bone Joint Surg Am 2004;86(1):22-27. DOI: 10.2106/00004623200401000-00005.

16. Gupta A, Singh S, Patel P, et al. Evaluation of the utility of the Ponseti method of correction of clubfoot deformity in a developing nation. Int Orthop 2008;32(1):75-79. DOI: 10.1007/s00264-006-0284-7.

17. Saif Ullah M, Ferdous KMN, Md. Shahjahan M, et al. Management of congenital talipes equino varus (CTEV) by Ponseti casting technique in neonates: our experience. J Neonatal Surg 2013;2(2):17. DOI: 10.47338/jns.v2.29.

18. Pirani $S$, Hodges $D$, Sekeramayi $F$, et al. A reliable and valid method of assessing the amount of deformity in the congenital club foot deformity. J Bone Joint Surg Br 2008;90(Suppl I):53.

19. Jain P, Mehtani A, Goel M, et al. Correlation of foot bimalleolar angle with Pirani score to assess the severity of congenital talipes equinovarus deformity. J Pediatr Orthop 2012;21B(1):68-72. DOI: 10.1097/BPB.0b013e32834adb56.

20. Goriainov V, Judd J, Uglow M. Does the Pirani score predict relapse in clubfoot? J Child Orthop 2010;4(5):439-444. DOI: 10.1007/s11832010-0287-1.

21. Gray K, Gibbons P, Little D, et al. Bilateral clubfeet are highly correlated: a cautionary tale for researchers. Clin Orthop Relat Res 2014;472(11):3517-3522. DOI: 10.1007/s11999-014-3776-6.
22. Bor N, Coplan JA, Herzenberg JE. Ponseti treatment for idiopathic clubfoot: minimum 5-year followup. Clin Orthop Relat Res 2009;467(5):1263-1270. DOI: 10.1007/s11999-008-0683-8.

23. Blakeslee TJ. Comparative radiographic analysis of congenital idiopathic talipes equinovarus (clubfoot) in infancy. A retrospective study. J Foot Surg 1988;27(3):189-205.

24. Bhatiwal SK, Chopra BL, Khajotia BL, et al. Idiopathic clubfoot treated by Ponseti method: a series of 300 cases. Int J Res Orthop 2018;4(6):954958. DOI: 10.18203/issn.2455-4510.IntJResOrthop20184383.

25. Saini MK, Vijay A, Gupta M, et al. Management of clubfoot by Ponseti method: a prospective study. J Orthop Allied Sci 2017;5(1):27-34.

26. Lehman WB, Ahamed M, Madan S. A method for the early evaluation of the Ponseti (lowa) technique for the treatment of idiopathic clubfoot. J Pediatr Orthop 2003;12B(2):133-140. DOI: 10.1097/00009957-200303000-00011.

27. Ponseti IV, Smoley EN. Congenital clubfoot: the results of treatment. J Bone Joint Surg Am 1963;45(2):2261-2275. DOI: 10.2106/00004623196345020-00004.

28. Morcuende JA, Abbasi D, Dolan LA, et al. Results of an accelerated Ponseti protocol for clubfoot. J Pediatr Orthop 2005;25(5):623-626. DOI: 10.1097/01.bpo.0000162015.44865.5e.

29. Sharma A, Shukla S, Kiran B, et al. Can the Pirani score predict the number of casts and the need for tenotomy in the management of clubfoot by the Ponseti method? Malaysian Orthop J 2018;12(1):26-30.

30. Porecha MM, Parmar DS, Chavda HR. Mid-term results of Ponseti method for the treatment of congenital idiopathic clubfoot (a study of 67 clubfeet with mean five year follow-up). J Orthop Surg Res 2011;6(3):1-7. DOI: 10.1186/1749-799X-6-3.

31. Scher DM, Feldman DS, van Bosse HJ, et al. Predicting the need for tenotomy in the Ponseti method for correction of clubfeet.J Pediatr Orthop 2004;24(4):349-352. DOI: 10.1097/01241398-20040700000001.

32. Kulambi V, Gaurav M, Naveen DS. Study of factors predicting the need for tenotomy in correction of clubfeet by Ponseti method. J Orthop Trauma Rehab 2017;9(1):38-40. DOI: 10.4103/0975-7341. 207160.

33. Prasad P, Sen RK, Gill SS, et al. Clinico-radiological assessment and their correlation in clubfeet treated with postero-medial soft-tissue release. Int Orthop 2009;33(1):225-229. DOI: 10.1007/s00264-0070448-0.

34. Shabtai L, Hemo Y, Yavor A, et al. Radiographic indicators of surgery and functional outcome in Ponseti-treated clubfeet. Foot Ankle Int 2016;37(5):542-547. DOI: 10.1177/1071100715623036.

35. Zimmerman CC, Nemeth BA, Noonan KJ, et al. Reliability of radiographic measures in infants with clubfoot treated with the Ponseti method. J Child Orthop 2015;9(2):99-104. DOI: 10.1007/ s11832-015-0647-y.

36. O'Halloran CP, Halanski MA, Nemeth BA, et al. Can radiographs predict outcome in patients with idiopathic clubfeet treated with the Ponseti method? J Pediatr Orthop 2015;35(7):734-738. DOI: 10.1097/ BPO.0000000000000354.

37. Lykissas MG, Crawford AH, Eismann EA, et al. Ponseti method compared with soft-tissue release for the management of clubfoot: a meta-analysis study. World J Orthop 2013;4(3):144-153. DOI: 10.5312/ wjo.v4.i3.144.

38. Hutchins $\mathrm{PM}$, Foster $\mathrm{BK}$, Paterson DC, et al. Long-term results of early surgical release in clubfeet. J Bone Joint Surg Br 1985;67(5):791-799. DOI: 10.1302/0301-620X.67B5.4055883.

39. Khanna M, Kumar M. Radiographic analysis of resistant and neglected clubfoot treated by fixator. J Foot Angle Surg (Asia-Pacific) 2015;2(2):71-73. DOI: 10.5005/jp-journals-10040-1032.

40. Shankar RK, Kotian P, Annappa R, et al. Radiological assessment of idiopathic club foot treated with Ponseti technique. J Clin Diag Res 2018;12(3):RC10-RC13. DOI: 10.7860/JCDR/2018/31616. 11289.

41. Radler C, Manner HM, Suda R, et al. Radiographic evaluation of idiopathic club foot undergoing Ponseti treatment. J Bone Joint Surg Am 2007;89(6):1177-1183. DOI: 10.2106/JBJS.F.00438. 